Article

\title{
Effective Interactions of Ag Nanoparticles on the Surface of SBA-15 in Performing Deep Desulfurization of Real Diesel Fuel
}

\author{
Clenildo de Longe ${ }^{1}$, Rafael Viana Sales ${ }^{1}$, Anne Beatriz Figueira Câmara ${ }^{1}$, \\ Heloise Oliveira Medeiros de Araújo Moura ${ }^{1}$, Enrique Rodríguez-Castellón ${ }^{2}{ }^{\mathbb{B}}$, \\ Sibele Berenice Castellã Pergher ${ }^{1}$ (D), Leila Maria Aguilera Campos ${ }^{3}$, Maritza Montoya Urbina ${ }^{4}$ \\ and Luciene Santos de Carvalho ${ }^{1, * \mathbb{D}}$ \\ 1 Energetic Technologies Research Group, Institute of Chemistry and School of Science and Technology, \\ Federal University of Rio Grande do Norte, Natal 59078-900, Brazil; clenildo_longe@hotmail.com (C.d.L.); \\ rafael_vianasales@hotmail.com (R.V.S.); anne.beatrizfc@gmail.com (A.B.F.C.); \\ helo.medeiros@outlook.com (H.O.M.d.A.M.); sibelepergher@gmail.com (S.B.C.P.) \\ 2 Department of Inorganic Chemistry, Crystallography and Mineralogy, College of Sciences, \\ University of Málaga, 29071 Málaga, Spain; castellon@uma.es \\ 3 Chemical Engineering Post-Graduate Program, Salvador University (UNIFACS), Salvador 40140-110, Brazil; \\ aguilera.leila@gmail.com \\ 4 Chemical Engineering, Center for Technology, Federal University of Alagoas, Maceió 57072-900, Brazil; \\ maritza@ctec.ufal.br \\ * Correspondence: luciene_car@hotmail.com; Tel.: +55-84-9-8828-5261
}

Received: 27 February 2020; Accepted: 10 April 2020; Published: 25 May 2020

\begin{abstract}
SBA-15 materials as-synthesized and impregnated with Ag nanoparticles were applied to perform adsorptive desulfurization of real diesel fuel. High-angle annular dark-field scanning transmission electron microscopy and field-emission scanning electron microscopy coupled with energy-dispersive X-ray spectroscopy (HAADF-STEM-EDX and FESEM-EDX) and X-ray photoelectron spectroscopy (XPS) results confirmed that there is uniform distribution of Ag nanodomains on the surface and in the channels of a 2AgSBA-15 ( $2 \% \mathrm{Ag})$ sample. The interaction between sulfur compounds and adsorbent mainly occurred via $\pi$-complexation mechanisms, as observed via XPS and equilibrium data. The kinetic results for 2AgSBA-15 were better fitted to the pseudo-second-order model $\left(R^{2}>0.9999\right)$, indicating that the determining step of the adsorptive process is chemisorption, whereas the equilibrium results were better fitted to the Langmuir model $\left(R^{2}>0.9994\right)$, thus indicating that the adsorption occurs on the adsorbent surface monolayer with significant adsorption capacity $\left(\mathrm{q}_{\mathrm{m}}=20.30 \mathrm{mgS} / \mathrm{g}\right)$, approximately two times greater than that observed for pure SBA-15. The mean desulfurization reached by the adsorbents was up to $86.8 \%$ for six recycling steps.
\end{abstract}

Keywords: SBA-15; Ag nanoparticles; chemisorptive desulfurization; $\pi$-complexation; XPS assessment

\section{Introduction}

In recent years, research on the development of ordered mesoporous materials has been increasingly focused on their application in catalysis and mitigation of environmental pollutants, mainly by adsorption [1,2]. Some remarkable features such as highly ordered and uniform porous structure, large pore volume, high thermal stability, and the easy obtainment and modification have attracted the interest of many researchers to microporous and mesoporous silica-based materials, such as zeolites [3], SBA-15 [4], KIT-6 [5], MSU-S [6], and MCM-41 [7]. 
Mesoporous silica SBA-15 has attracted a lot of attention in many areas such as catalysis, nanomedicine, and adsorption due to its large surface area, high thermal and water stabilities, interconnected pore systems, and thick walls [8]. This material presents peculiar characteristics that are interesting for adsorption and catalysis processes, such as some micropores present next to the hexagonally ordered mesoporosity, high surface area, and uniform pore size. However, its structure is neutral in charge and does not significantly interact with organic pollutants. Thus, incorporating metal nanoparticles is the key to enhancing the adsorption of several contaminants [9].

Catalysts based in $d$-block metals on mesoporous silica have proven to be very effective at removing organic sulfur from diesel oil due to their unique physicochemical properties $[10,11]$, constituting a technological issue in the petroleum industry. These metals are capable of enhancing the adsorption of S-compounds through $\pi$-complexation or other metal/sulfur interactions, being significantly stronger than van der Waals interactions, and thus leading to a higher adsorption selectivity [12,13]. Modifying supports with silver nanosites is able to improve the catalytic and adsorptive performance of the supports due to the higher desulfurization capacity in environmental conditions and the good regenerability of the materials [14].

The hydrodesulfurization (HDS) process is the conventional method [15] used in refineries for desulfurization, despite the elevated temperature $\left(350-400{ }^{\circ} \mathrm{C}\right)$ and pressure $(3-10 \mathrm{MPa})$ required, in addition to the low efficiency to remove thiophenes and its derivatives $[16,17]$. Thus, the adsorptive method becomes an alternative due to its simplicity, low cost, efficiency, and possibility of working in multiple adsorption-desorption cycles [7,18]. Furthermore, such a process does not cause alterations in the physical properties of the fuel [19]. The demand for low-cost and high-performance materials has drawn the attention to alternative sources.

The present study contributes by applying SBA-15 mesoporous material as-synthesized and modified with $\mathrm{Ag}$ and $\mathrm{Ni}$ in a cleaner alternative methodology for producing low-sulfur content diesel fuel by adsorptive desulfurization. X-ray photoelectron spectroscopy (XPS) as well as high-angle annular dark-field scanning transmission electron microscopy and field-emission scanning electron microscopy coupled with energy-dispersive X-ray spectroscopy (HAADF-STEM-EDX and FESEM-EDX) techniques were used to assess the efficiency of the synthesis and impregnation steps. Diverse kinetic and equilibrium models were applied in order to evaluate the adsorption process, thus providing information and enabling employment of a lower cost method in comparison to the currently used process in petroleum refineries.

\section{Results and Discussion}

\subsection{Preliminary Adsorption Data}

The results indicate that the functionalized adsorbents present higher desulfurization capacity due to the stronger interaction of the transition metals with the organosulfur compounds. Higher adsorption was obtained for 8AgSBA-15 ( $8 \% \mathrm{Ag})$; however, it was not significant in comparison to the adsorbent impregnated with $2 \% \mathrm{Ag}$. Hence, the concentration of $2 \% \mathrm{Ag}$ was applied for further adsorptive studies and main characterization analysis due to its satisfactory performance and cost-benefit ratio. Figures S1 and S2 (Supplementary Materials) present the results of sulfur adsorption performance for the materials studied and the X-ray diffraction (XRD) patterns for the adsorbents with $8 \% \mathrm{Ag}, 2 \% \mathrm{Ni}$, and $8 \% \mathrm{Ni}$ over SBA-15, respectively.

\subsection{Characterization of the Materials}

The XRD patterns of SBA-15 and 2AgSBA-15 are depicted in Figure 1. As observed in Figure 1a, three well-defined peaks at $2 \theta=0.77^{\circ}, 1.39^{\circ}$ and $1.62^{\circ}$ are ascribed to the diffraction planes (100), (110), and (200), respectively, which are typical of the highly ordered two-dimensional hexagonal structure of SBA-15 [20-22]. This well-ordered 2D pore structure of SBA-15 mesoporous silica was preserved after impregnation with $\mathrm{Ag}(\mathrm{I})$ (Figure 1a). 

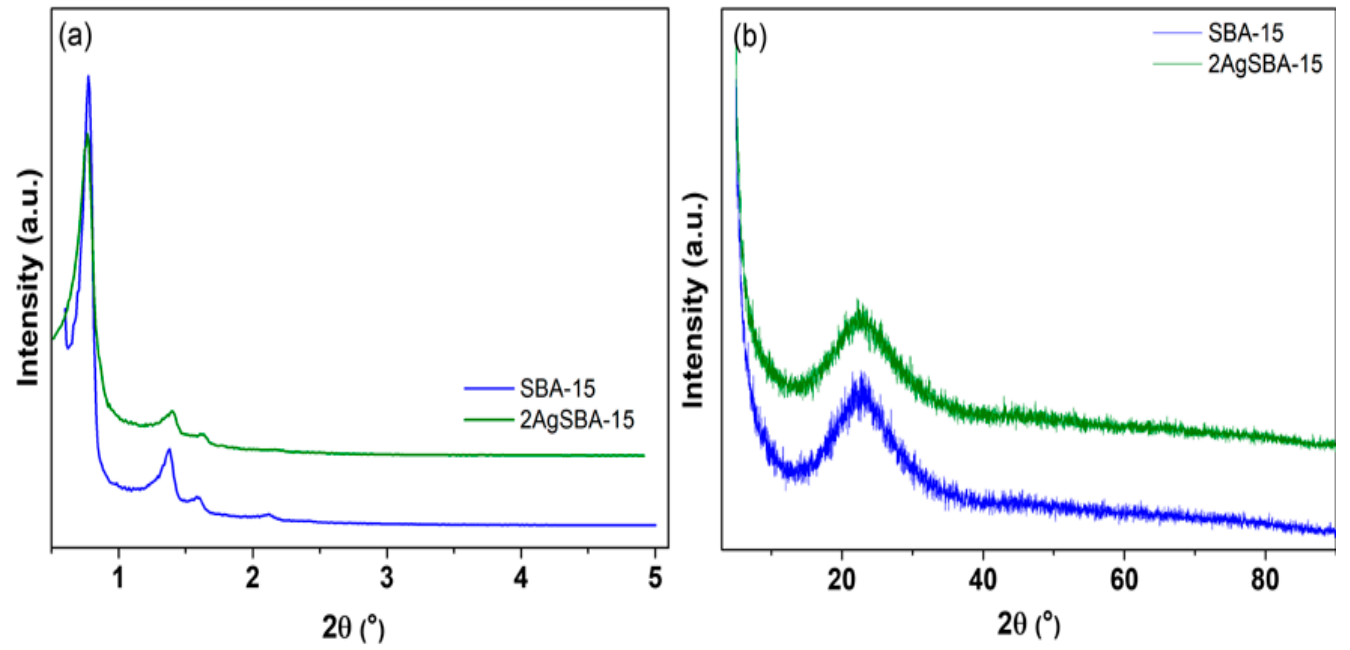

Figure 1. (a) Low-angle and (b) wide-angle X-ray diffractograms for SBA-15 and 2AgSBA-15 adsorbents.

Wide-angle XRD patterns (Figure $1 \mathrm{~b}$ ) only exhibit a wide peak centered at $2 \theta 22.5^{\circ}$, which is attributed to the amorphous silica wall. The absence of peaks relative to the sample impregnated with silver (2AgSBA-15) may indicate that Ag species are highly dispersed and present high interaction with the mesoporous support. In addition, the size of these species may be below the equipment detection limit in the form of nanoparticles $(<3 \mathrm{~nm})$ [23-25].

The $\mathrm{N}_{2}$ adsorption-desorption isotherms performed before and after $\mathrm{Ag}$ modification are shown in Figure 2, as well as the pore size distribution plot. The isotherms for both samples are classified as Type IV, characteristic of mesoporous materials according to the International Union of Pure and Applied Chemistry (IUPAC) classification, with an H1 hysteresis cycle, which indicates narrow and uniform pore size distribution [26-28]. The pore size distribution plot indicates that the adsorbents have uniform mesopore sizes with maximum distribution in the range of 87-95 $\AA$. The incorporation of $\mathrm{Ag}$ species to the mesoporous support did not cause significant changes in the isotherm profile.

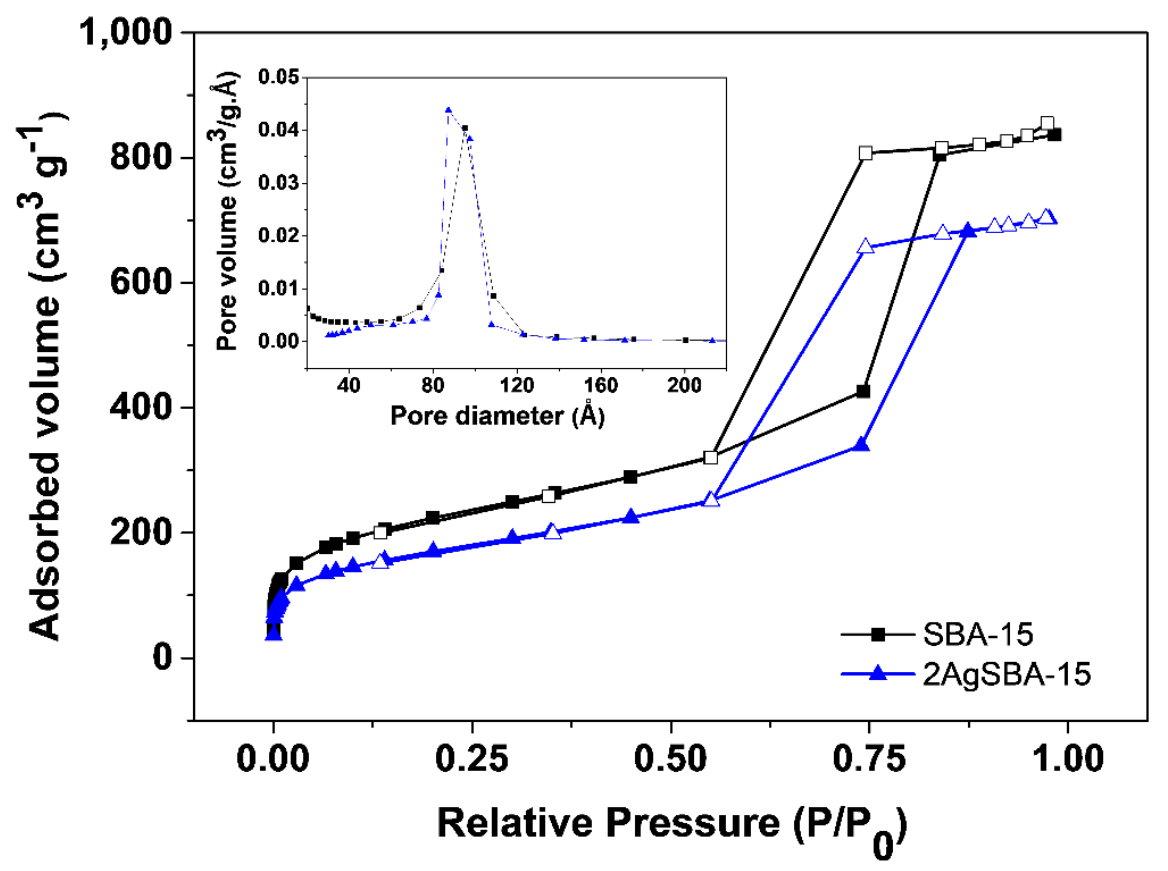

Figure 2. $\mathrm{N}_{2}$ adsorption-desorption isotherms at $77 \mathrm{~K}$ and the corresponding Barrett-Joyner-Halenda $(\mathrm{BJH})$ adsorption pore size distributions for the adsorbents. 
The textural parameters of SBA-15 and 2AgSBA-15 adsorbents are summarized in Table 1. The reduction in specific surface area and total pore volume in relation to the original material suggests that there was pore occlusion by the deposited Ag species [26,27,29].

Table 1. Textural properties of the adsorbents.

\begin{tabular}{cccc}
\hline Adsorbent & $\mathbf{S}_{\text {BET }}{ }^{\mathbf{1}}\left(\mathbf{m}^{\mathbf{2}} / \mathbf{g}\right)$ & $\mathbf{V}_{\mathbf{P}}{ }^{\mathbf{2}}\left(\mathbf{c m}^{\mathbf{3}} / \mathbf{g}\right)$ & Maximum Pore Diameter $(\AA)$ \\
SBA-15 & 757 & 1.32 & 95 \\
2AgSBA-15 & 576 & 1.10 & 87
\end{tabular}

\footnotetext{
${ }^{1}$ Specific surface area calculated using the Brunauer-Emmett-Teller (BET) equation. ${ }^{2}$ Total pore volume at
} $\mathrm{P} / \mathrm{P}_{0}=0.996$.

HAADF-STEM images for pure SBA-15 (Figure 3a,b) confirm the well-ordered mesoporous hexagonal structure of the SBA-15 matrix [30-32]. As shown in Figure 3c, the structure of the original material was preserved after modification with $\operatorname{Ag}(\mathrm{I})$, which is in line with the previous characterization results. Some silver nanoparticle clusters can be observed (Figure 3c); however, HAADF-STEM-EDX mapping images (Figure 3d) revealed uniform distribution of silver nanoparticles over the sustainable SBA-15 material.

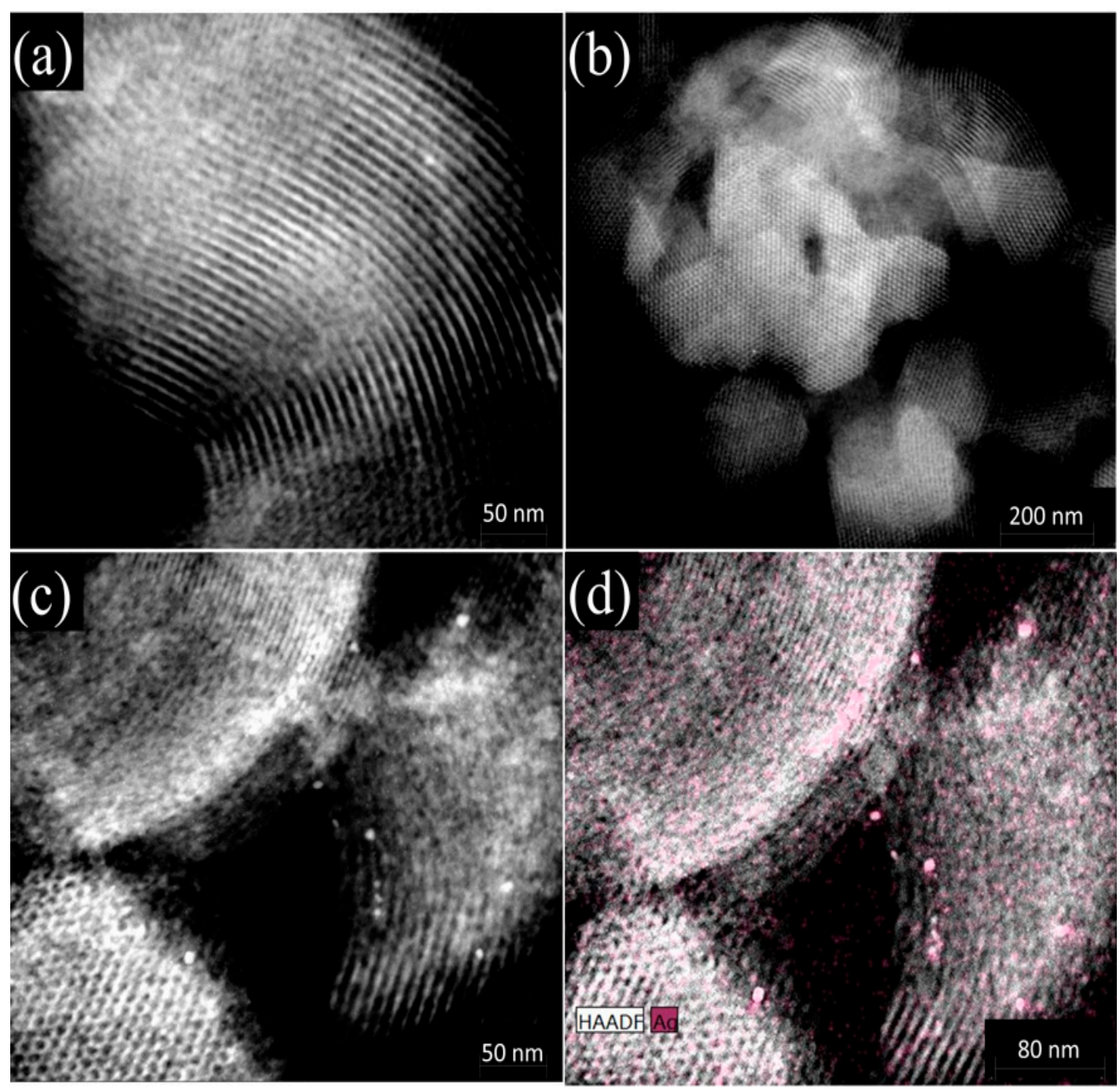

Figure 3. (a,b) High-angle annular dark-field scanning transmission electron microscopy (HAADF-STEM) micrograph for pure SBA-15; (c) HAADF-STEM and (d) HAADF-STEM coupled with energy-dispersive X-ray spectroscopy (HAADF-STEM-EDX) mapping images for 2AgSBA-15. 
The FESEM micrograph for the 2AgSBA-15 sample, illustrated in Figure 4a, revealed a uniform long-fiber shape morphology [33]. The mapping images (Figure $4 \mathrm{~b}-\mathrm{d}$ ) show a homogeneous dispersion of Ag particles over the silica surface (O-Si-O), which is consistent with the HAADF-STEM-EDX results. The elemental composition of the 2AgSBA-15 sample obtained by EDX is depicted in Figure 4e.
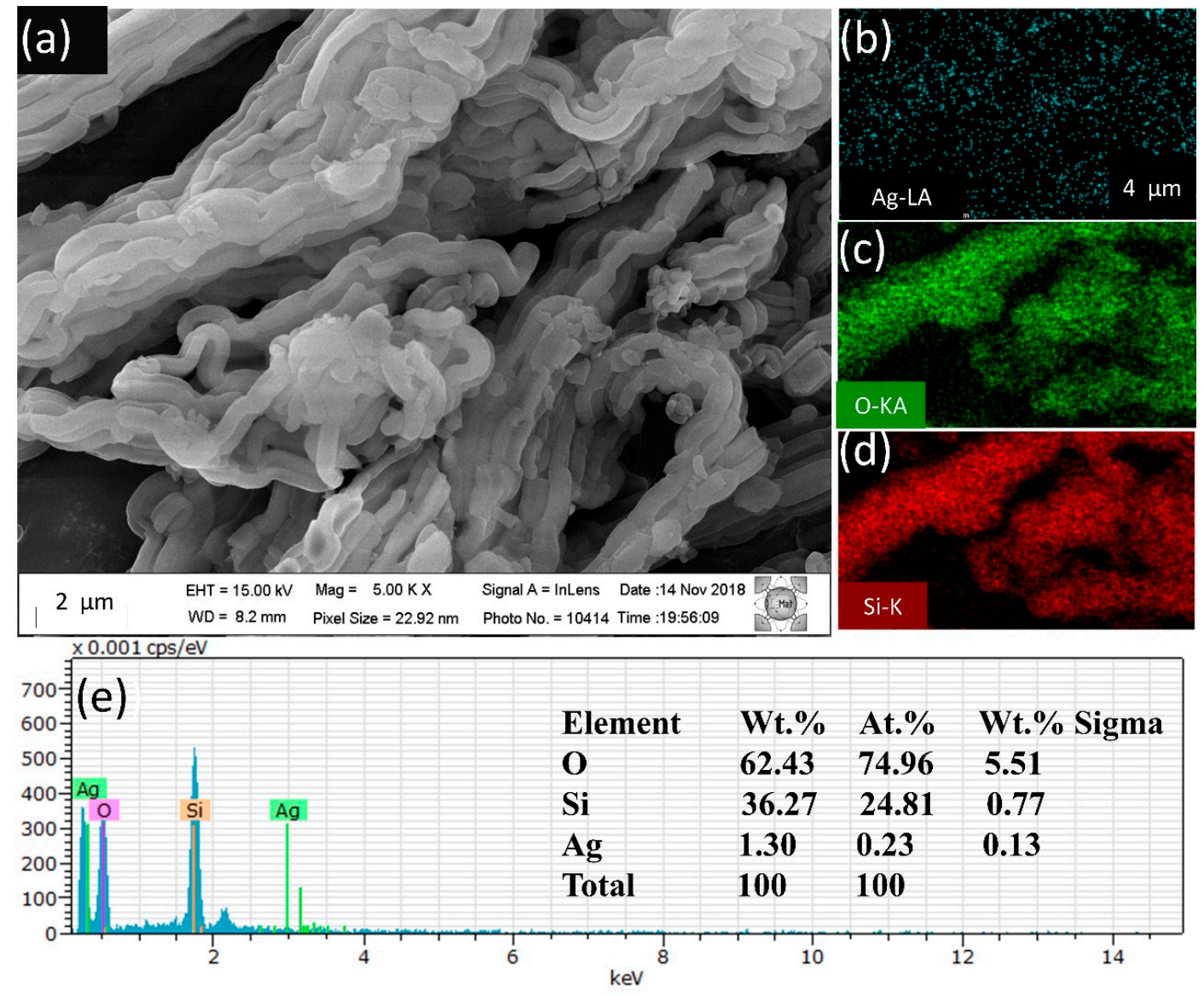

Figure 4. (a) Field-emission scanning electron microscopy (FESEM); (b-d) elemental mapping and (e) EDX spectrum obtained for 2AgSBA-15.

X-ray photoelectron spectroscopy (XPS) was used to evaluate the electronic properties of the surface species, including their oxidation states, binding energies, and the electronic atmosphere [34]. The XPS survey spectra of 2AgSBA-15 and 2AgSBA-15 S samples are depicted in Figure 5, which shows the sample before and after desulfurization, respectively. It is possible to observe the presence of $\mathrm{Ag}, \mathrm{O}, \mathrm{Si}$, and $\mathrm{C}$ elements in both adsorbents. The presence of $\mathrm{C}$ is associated with the adventitious contamination. The photoemission peaks at 103.3 and $532.6 \mathrm{eV}$ are assigned at $\mathrm{Si} 2 p$ and $\mathrm{O} 1 \mathrm{~s}$ of the silica in 2AgSBA-15 [24,35,36]. The presence of sulfur was not detected, probably due to its low surface concentration.

The deconvoluted Ag $3 d$ core level spectra for the 2AgSBA-15 sample before and after desulfurization are depicted in Figure 6. The deconvolutions reached significant correlation coefficient $\left(\mathrm{R}^{2}>0.998\right)$ and $\mathrm{F}$ values $(>4308.8)$ with a low standard error $(<13.78)$. The lower $\mathrm{F}$ value for the deconvolution of 2AgSBA-15 $\mathrm{S}$ is related to the higher noise presented in the spectra of the adsorbent after desulfurization, since a severe Savitzky-Golay smoothing was not used in order to maintain the real features of the data without overfitting. The $\mathrm{Ag} 3 d_{5 / 2}-\mathrm{Ag} 3 d_{3 / 2}$ doublet at 367.8 and $373.8 \mathrm{eV}$, respectively (Figure 6a), is assigned to $\mathrm{Ag}(\mathrm{I})$ species chemically bonded to oxygen atoms, which may mainly occur by interactions with the silanol groups of SBA-15 (Ag-O-Si) [37], while the peaks at $369.2 \mathrm{eV}$ and $374.9 \mathrm{eV}$ are ascribed to metallic $\mathrm{Ag}$ sub-nanoparticles $(<4 \mathrm{~nm})$ widely dispersed over the support [38,39]. 


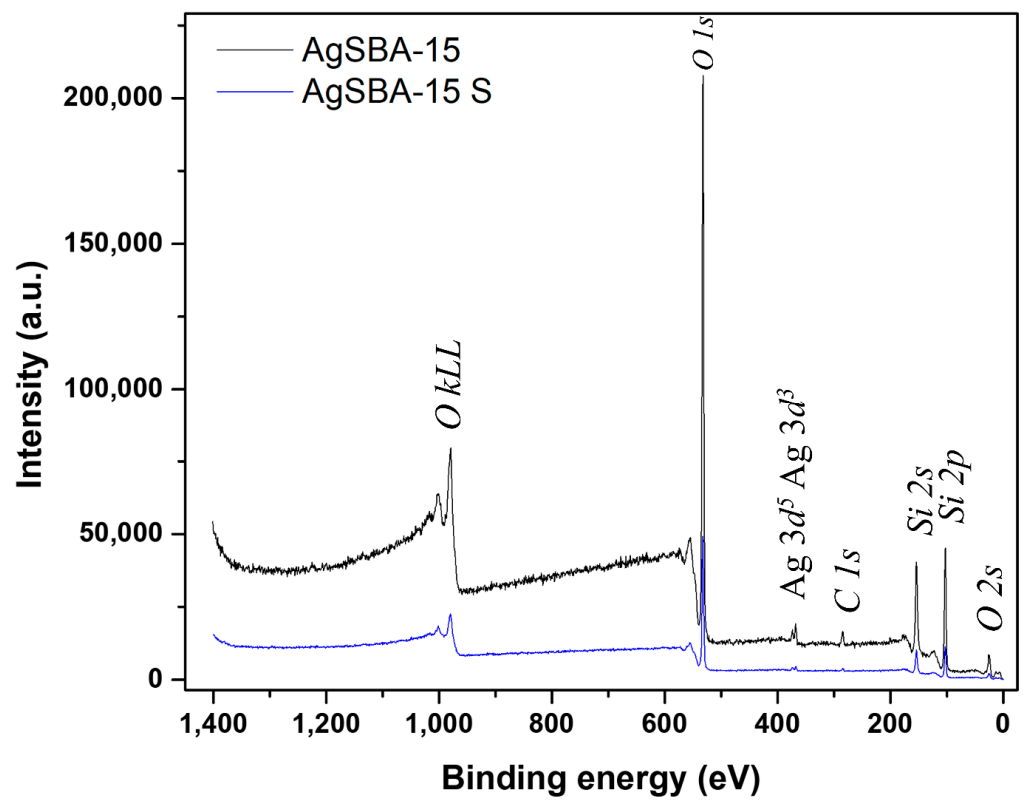

Figure 5. X-ray photoelectron spectroscopy (XPS) spectra for 2AgSBA-15 and 2AgSBA-15 S.

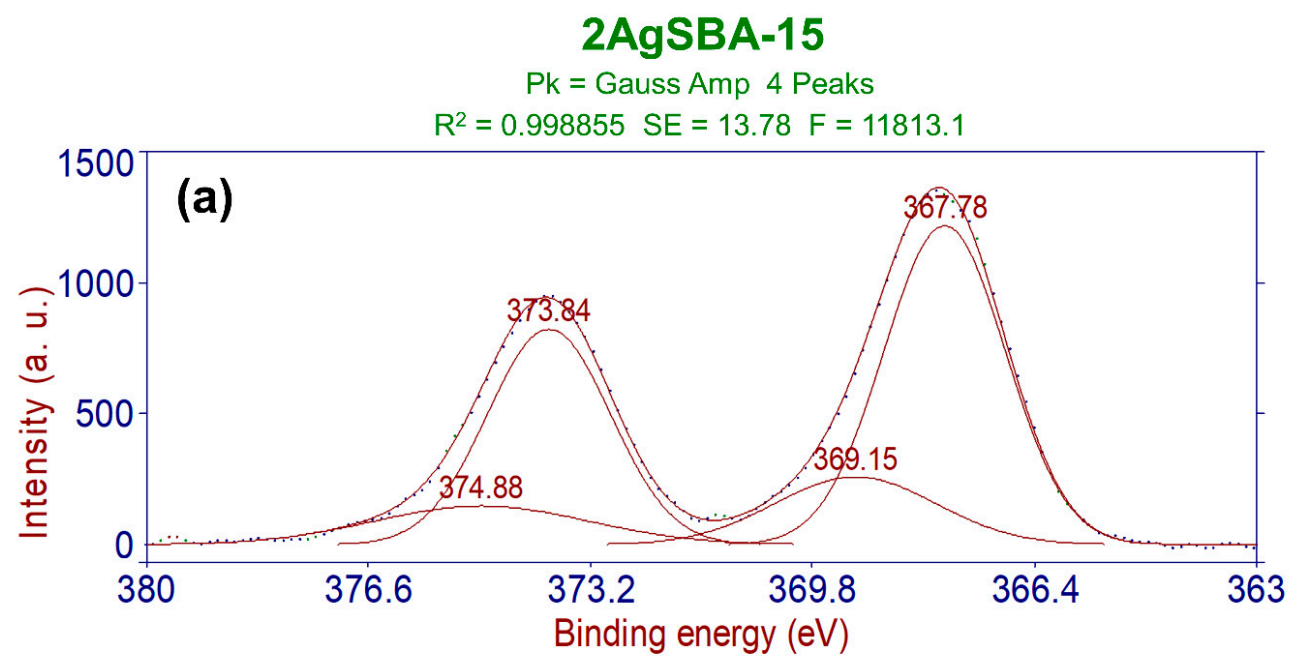

2AgSBA-15 S

$P k=$ Gauss Amp 6 Peaks

$\mathrm{R}^{2}=0.998052$ SE $=4.98 \quad \mathrm{~F}=4308.83$

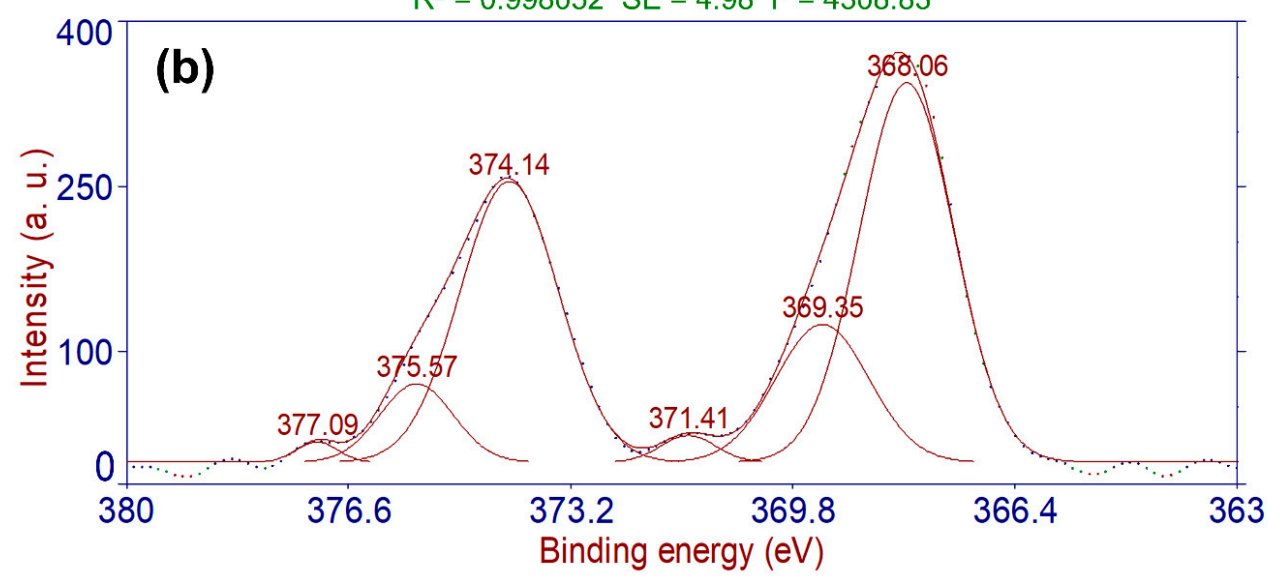

Figure 6. Deconvoluted Ag $3 d$ core level spectra for (a) 2AgSBA-15 and (b) 2AgSBA-15 S. 
It can be seen that the binding energies increased after the desulfurization tests (Figure $6 \mathrm{~b}$ ), thus indicating a less negative charge of Ag species due to the electron transfer caused by $\pi$-backbonding complexation between these silver nanosites and the sulfur molecules (Ag-S-R, S-R = DBT) $[40,41]$, which controls the chemisorption process. Furthermore, a small doublet related to a new Ag species emerged at $371.4 \mathrm{eV}$ and $377.1 \mathrm{eV}$, which were previously ascribed in the literature as "anomalous chemical shifts" present in XPS spectra of sulfur containing Ag molecules [42]. Thus, the recorded XPS data proved that the Ag species on the SBA-15 surface are able to drive the organosulfur adsorption by chemisorption processes, thus enhancing the desulfurization performance.

The Ag MNN Auger lines were also recorded; however, these signals are very noisy and presented low intensity due to the low silver content, and therefore are not helpful for studying the chemical states of silver.

\subsection{Adsorption Kinetics}

Pseudo-first-order, pseudo-second-order, Elovich, intraparticle diffusion, and Boyd's film-diffusion kinetic models were used to test the experimental data and evaluate the controlling mechanism of the sulfur adsorption process. The fitting for the kinetic data of the studied adsorbents depicted in Table 2 and Figures 7 and 8 summarize the estimated parameters and the determination coefficients $\left(R^{2}\right)$ of the models. The plot of the amount of sulfur adsorbed per time for 2AgSBA-15 and AgSBA-15 is depicted in Figure S3 of the Supplementary Materials.

Table 2. Kinetic test results for the pseudo-first-order, pseudo-second-order, intraparticle diffusion, and Elovich equations.

\begin{tabular}{|c|c|c|}
\hline \multirow{2}{*}{ Model or Parameter } & \multicolumn{2}{|c|}{ Adsorbent } \\
\hline & SBA-15 & 2AgSBA-15 \\
\hline qexp & 3.085 & 5.221 \\
\hline \multicolumn{3}{|l|}{ Pseudo-first-order model } \\
\hline $\mathrm{q}_{\mathrm{e}}(\mathrm{mg} / \mathrm{g})$ & 0.253 & 0.273 \\
\hline $\mathrm{k}_{1}\left(\min ^{-1}\right)$ & 0.029 & 0.005 \\
\hline $\mathrm{R}^{2}$ & 0.8810 & 0.8904 \\
\hline \multicolumn{3}{|c|}{ Pseudo-second-order model } \\
\hline $\mathrm{q}_{\mathrm{e}}(\mathrm{mg} / \mathrm{g})$ & 3.115 & 5.219 \\
\hline $\mathrm{k}_{2}(\mathrm{~g} /(\mathrm{mg} \min ))$ & 0.365 & 0.107 \\
\hline$R^{2}$ & 0.9999 & 0.9999 \\
\hline \multicolumn{3}{|l|}{ Intraparticle diffusion } \\
\hline $\mathrm{k}_{\mathrm{id}}(\mathrm{mg} /(\mathrm{g} \min ))$ & 0.037 & 0.008 \\
\hline $\mathrm{C}(\mathrm{mg} / \mathrm{g})$ & 2.7438 & 4.973 \\
\hline$R^{2}$ & 0.5532 & 0.606 \\
\hline \multicolumn{3}{|l|}{ Elovich } \\
\hline$\alpha(\mathrm{mg} /(\mathrm{g} \min ))$ & $2.37 \times 10^{10}$ & 57.33 \\
\hline$\beta(\mathrm{g} / \mathrm{mg})$ & 0.118 & 20.47 \\
\hline $\mathrm{R}^{2}$ & 0.7601 & 0.8402 \\
\hline \multicolumn{3}{|l|}{ Boyd } \\
\hline $\mathrm{B}^{1}$ & 0.002 & 0.005 \\
\hline $\mathrm{R}^{2}$ & 0.7857 & 0.9034 \\
\hline
\end{tabular}

${ }^{1} \mathrm{~B}$ is Boyd's constant, angular coefficient of Boyd's graph $\left(\mathrm{t} \times \mathrm{B}_{\mathrm{t}}\right)$.

The pseudo-first-order model did not present satisfactory fitting to the studied data, with a low $R^{2}$ value $\left(R^{2}<0.8904\right)$ and a large discrepancy between the calculated and experimental maximum adsorption capacities $\left(q_{e}\right)$, thus limiting its applicability. The experimental results of the studied adsorbents were better adjusted to the pseudo-second-order model, as can be seen in Figures 7 and 8 and Table 2, since the determination coefficient was near $1\left(R^{2}>0.9999\right)$. Moreover, the differences between 
the experimental and calculated $q_{e}$ values were lower than those obtained by the pseudo-first-order model. This kinetic model indicated that the rate-determining step is chemisorption, which involves valence forces through sharing or exchanging electrons between adsorbent/adsorbate [43]. It is notable that the 2AgSBA-15 data presented a higher fit to this model than the pure material, since the interactions between the transition metal active sites and the adsorbate, such as $\pi$-complexation, are considerably stronger than the predominant van der Waals forces present in the SBA-15 support [44]. The Elovich equations were also evaluated, but they were not able to fit the experimental data $\left(R^{2}>0.7601\right)$.
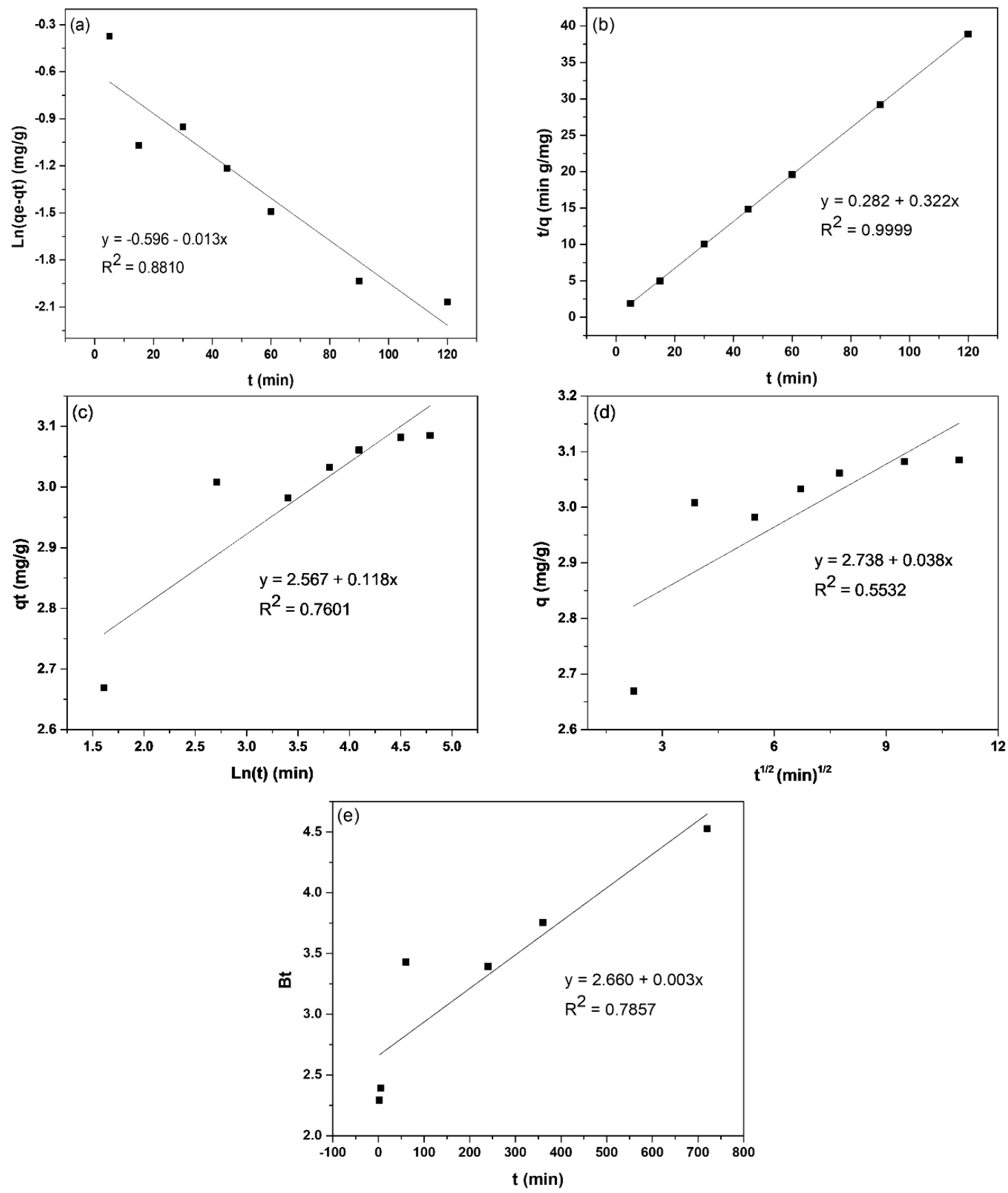

Figure 7. Fittings for SBA-15: (a) pseudo-first-order, (b) pseudo-second-order, (c) Elovich, (d) intraparticle diffusion, and (e) Boyd models. 

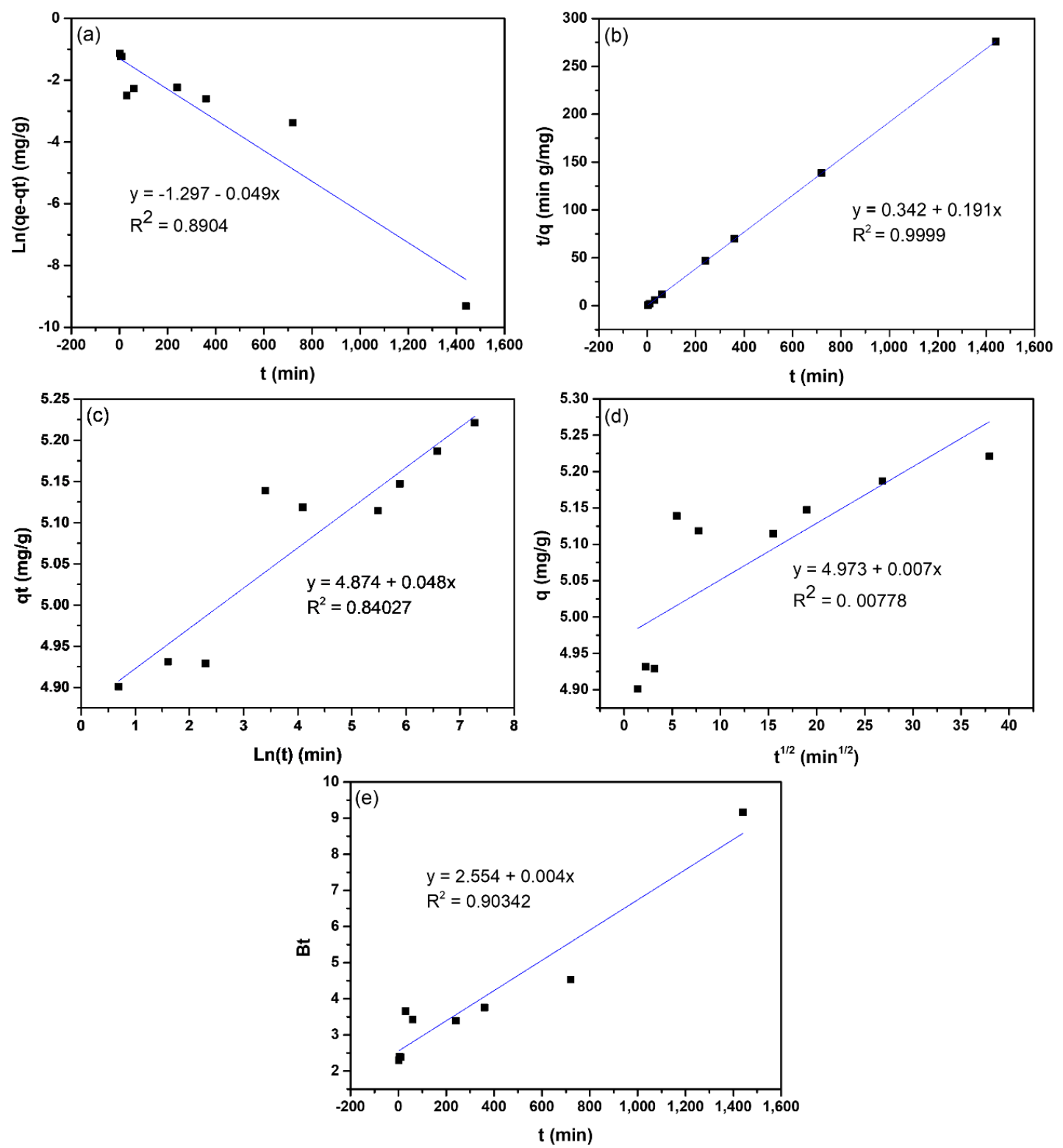

Figure 8. Fittings for 2AgSBA-15: (a) pseudo-first-order, (b) pseudo-second-order, (c) Elovich, (d) intraparticle diffusion, and (e) Boyd models.

Finally, the influence of diffusion and the mechanism which controls mass-transfer resistance on the adsorption rate were assessed by the intraparticle diffusion and Boyd's film-diffusion models. The SBA-15 and 2AgSBA-15 adsorbents did not present a good fit to the intraparticle diffusion model $\left(R^{2}>0.606\right)$. The fact that none of the regression lines passed through the origin (Figures 7 and 8 ) imply that the intraparticle diffusion may not be the only rate-determining step, and suggest the occurrence of additional processes involved in the adsorption mechanism [45]. The positive $C$ constant value suggests fast adsorption of sulfur compounds [46]. However, the 2AgSBA-15 data could be fitted to the Boyd's film diffusion $\left(R^{2}>0.9034\right)$, and the plot not being linear (Figure 8 ) suggests that the pore diffusion is not the rate-controlling step mechanism [47], further indicating that significantly strong chemical interactions are the main forces which govern the adsorptive desulfurization over 2AgSBA-15.

\subsection{Adsorption Equilibrium Isotherms}

Langmuir, Freundlich, Temkin, and Dubinin-Radushkevich (D-R) isotherms were applied to evaluate the relation between adsorbate/adsorbent when the adsorption process reaches equilibrium at 
different initial concentrations, as depicted in Figure 9. The parameters and $\mathrm{R}^{2}$ of the isotherm models (Table 3) for the studied adsorbents reveal that the Ag sites on SBA-15 provided high adsorptive capacity to the material, as seen in the $q_{m}$ values.
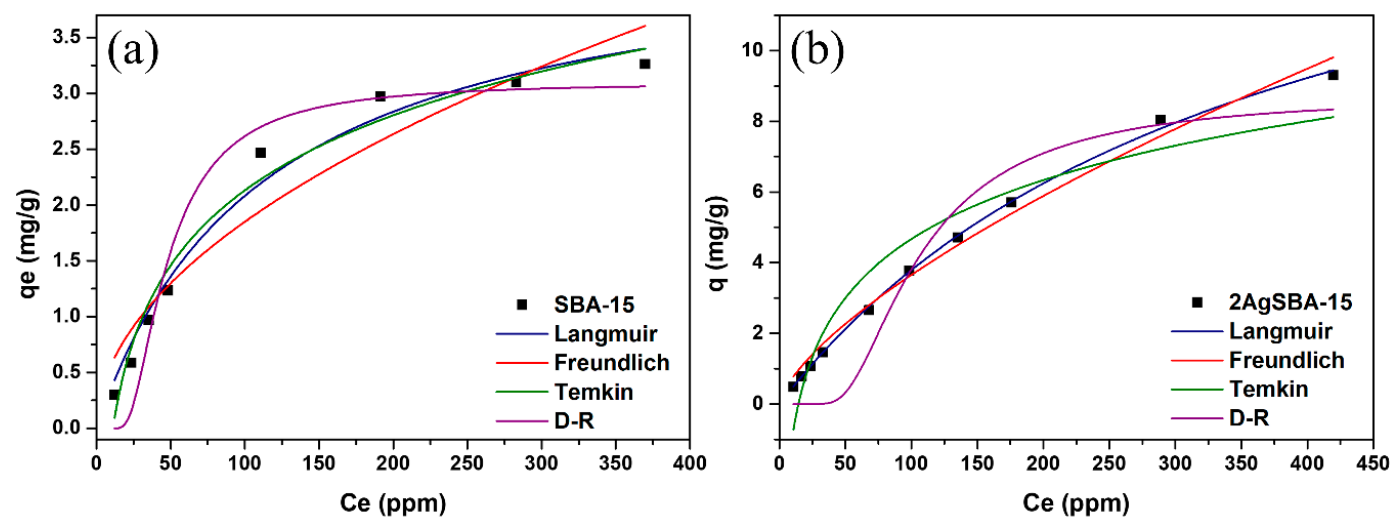

Figure 9. Nonlinear fittings of Langmuir, Freundlich, Temkin, and Dubinin-Radushkevich (D-R) equilibrium equations for sulfur adsorption over (a) SBA-15 and (b) 2AgSBA-15.

Table 3. Fitting parameters for sulfur adsorption equilibrium data of SBA-15 and 2AgSBA-15 to Langmuir, Freundlich, Temkin, and Dubinin-Radushkevich (D-R) equations.

\begin{tabular}{cccc}
\hline \multirow{2}{*}{ Isotherm } & \multirow{2}{*}{ Parameter } & \multicolumn{2}{c}{ Adsorbent } \\
\cline { 3 - 4 } & & SBA-15 & 2AgSBA-15 \\
\hline Langmuir & $\mathrm{K}_{\mathrm{L}}(\mathrm{L} / \mathrm{mg})$ & 0.0024 & 0.0023 \\
& $\mathrm{q}_{\mathrm{m}}(\mathrm{mg} / \mathrm{g})$ & 10.62 & 20.30 \\
& $\mathrm{R}^{2}$ & 0.9909 & 0.9994 \\
\hline Freundlich & $\mathrm{K}_{\mathrm{F}}$ & 0.0696 & 0.079 \\
& $\mathrm{n}$ & 1.39 & 1.22 \\
& $\mathrm{R}^{2}$ & 0.9412 & 0.9909 \\
\hline Temkin & $\alpha$ & 0.0900 & 0.069 \\
& $\beta$ & 0.96 & 2.406 \\
& $\mathrm{R}^{2}$ & 0.9787 & 0.9169 \\
\hline $\mathrm{D}-\mathrm{R}$ & $\mathrm{q}_{\mathrm{s}}$ & 10.29 & 4.087 \\
& $\beta$ & $5 \times 10^{-7}$ & $5.318 \times 10^{-5}$ \\
& $\mathrm{E}$ & 1000 & 96.964 \\
& $\mathrm{R}^{2}$ & 0.5066 & 0.6242 \\
\hline
\end{tabular}

The Langmuir, Freundlich, and Temkin models showed a good fit to the adsorption equilibrium data of all the studied adsorbents. However, the equilibrium results did not fit the D-R model $\left(R^{2}<0.5066\right)$. Moreover, the good fit of the Langmuir model $\left(R^{2}>0.9909\right)$ to the equilibrium data of all the adsorbents suggests monolayer adsorption on the adsorbent surface with a finite number of sites [48]. The $0<R_{L}<1$ obtained for these materials indicates favorable adsorption of S-compounds [45]. It was possible to observe an increment in the maximum adsorption capacity of S-compounds (from $10.62 \mathrm{mg} / \mathrm{g}$ to $20.30 \mathrm{mg} / \mathrm{g}$ ) of 2AgSBA-15, indicating the occurrence of chemisorption mechanisms such as $\pi$-complexation in the process [41].

The Freundlich isotherm model presented the second-best fit to the experimental data for SBA-15 (Figure 9a) and 2AgSBA-15 (Figure $9 b)\left(R^{2}>0.9412\right)$, and indicates a favorable adsorption process in heterogeneous systems or multilayer adsorption (Freundlich, 1906). For instance, the $n$ values higher than 1 obtained for 2AgSBA-15 suggest that the adsorptive desulfurization was a favorable process [49]. Regarding the Temkin model, there is a linear decrease of the adsorption heat in the adsorbate molecules when the adsorbent layer is covered, thus suggesting maximum uniform energy distribution over the adsorbents' surface [45], which can be considered for both adsorbents $\left(R^{2}>0.9169\right)$. The adsorptive 
capacity of the 2AgSBA-15 sample is superior or similar when compared to other materials applied in fuel desulfurization, as shown in Table 4.

Table 4. Comparison of sulfur adsorption performance data for some materials studied in literature.

\begin{tabular}{|c|c|c|c|c|}
\hline Adsorbent & Feedstock & Conditions & $\mathrm{q}_{\mathrm{m}}{ }^{\mathrm{a}}(\mathrm{mg} / \mathrm{g})$ & Reference \\
\hline Alumina & DBT & $25^{\circ} \mathrm{C}$ & 21.02 & [50] \\
\hline NaY Zeolite & DBT; 4,6-DMDBT & room temperature & $6.7 ; 1.7$ & [51] \\
\hline Activated carbons & DBT & room temperature, $\mathrm{Cu}^{+}$ & 19.0 & [52] \\
\hline $\mathrm{TiO}_{2} / \mathrm{SBA}-15$ & DBT & $35^{\circ} \mathrm{C}$ & $19.3 ; 12.7 ; 7.2$ & [53] \\
\hline $\mathrm{Cu}(\mathrm{I}) / \mathrm{SBA}-15(30)$ & Tiophene & $30{ }^{\circ} \mathrm{C}, 6.27 \%$ de $\mathrm{Cu}(\mathrm{wt} \%)$ & 21.85 & [54] \\
\hline $10 \mathrm{Cu} / \mathrm{SBA}-15$ & Tiophene & room temperature & 14.33 & {$[4]$} \\
\hline $\mathrm{AC} / \mathrm{Ce} / \mathrm{Fe}$ & Tiophene, BT, DBT & & $0.33 ; 2.48 ; 3.70$ & [55] \\
\hline $\begin{array}{l}\text { MMZ; 5Ni/MMZ; 10Ni/MMZ; } \\
\text { UR.10Ni/MMZ; 15Ni/MMZ }\end{array}$ & Tiophene & room temperature & $\begin{array}{l}16.96 ; 21.37 ; 23.98 ; \\
9.095 ; 10.87\end{array}$ & [56] \\
\hline MCM-41 & Diesel fuel & $25^{\circ} \mathrm{C}$ & 3.06 & [9] \\
\hline $\mathrm{AgNO}_{3}$ or $\mathrm{Ag}_{2} \mathrm{O} / \mathrm{MCM}-41$ & Diesel fuel & $25^{\circ} \mathrm{C}, 2 \% \mathrm{Ag}$ & $31.25 ; 13.95$ & \\
\hline $\mathrm{Ni}\left(\mathrm{NO}_{3}\right)_{2}$ or $\mathrm{NiO} / \mathrm{MCM}-41$ & Diesel fuel & $25^{\circ} \mathrm{C}, 2 \% \mathrm{Ni}$ & $8.97 ; 5.38$ & [9] \\
\hline MCM-41 or AgMCM-41 & Diesel fuel & $25^{\circ} \mathrm{C}, 2 \% \mathrm{Ag}$ & $7.25 ; 15.41$ & [23] \\
\hline Palygorskite & Diesel fuel & $45^{\circ} \mathrm{C}$ & 6.25 & [57] \\
\hline SBA-15 & Diesel fuel & $25^{\circ} \mathrm{C}$ & 10.62 & This study \\
\hline 2AgSBA-15 & Diesel fuel & $25^{\circ} \mathrm{C}, 2 \% \mathrm{Ag}$ & 20.30 & This study \\
\hline
\end{tabular}

${ }^{a}$ Maximum adsorption capacity obtained by the Langmuir model (Equation (5)).

The molecular components of model diesel are smaller when compared to those in real diesel, as well as their respective critical diameters [58]. Thus, the best way to evaluate the adsorption capacity of an adsorbent is by performing desulfurization tests with real diesel. For effective adsorption of large molecules, the pore size of the adsorbent should not only be, at a minimum, larger than the critical diameter of the adsorbate, but should also be sufficiently large to reduce diffusional resistance during adsorption [59]. Both the SBA-15 and 2AgSBA-15 materials presented satisfactory reuse rates with a low decrease in sulfur adsorption after six regeneration cycles with the solvent mixture, thus indicating significant organosulfur removal by the adsorbents for many recycling steps, as shown in Figure 10. The main organosulfur components of real diesel and their critical diameters are depicted in Tables S1 and S2 of the Supplementary Material, respectively.

$\square$ SBA-15 $\square$ AgSBA-15

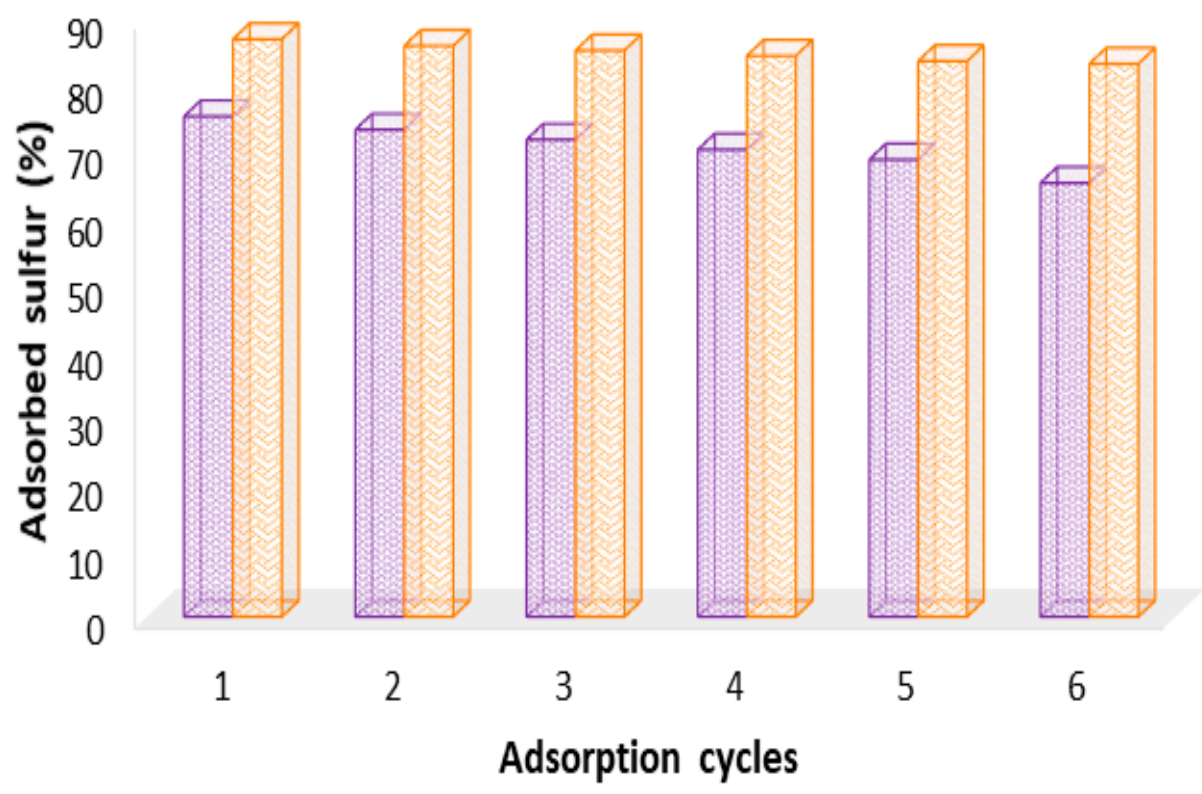

Figure 10. S-adsorption results for six recycles with the regenerated SBA-15 and 2AgSBA-15 materials. 


\section{Materials and Methods}

\subsection{Reagents}

The following reagents were used: hydrochloric acid $(\mathrm{HCl}, 37 \%$, PA, Vetec|Sigma-Aldrich, Duque de Caxias, RJ, Brazil); ethanol $\left(\mathrm{C}_{2} \mathrm{H}_{6} \mathrm{O}, 99.5 \%\right.$, NEON, São Paulo, SP, Brazil); tetraethyl orthosilicate (TEOS, 99.999\%, Sigma-Aldrich, St. Louis, MO, USA); poly(ethylene oxide)-poly(propylene oxide)-poly(ethylene oxide) triblock copolymer (Pluronic P123, 98\%, Sigma-Aldrich, St. Louis, MO, USA); silver nitrate ( $\mathrm{AgNO}_{3}, 99.8 \%$, Vetec|Sigma-Aldrich, Duque de Caxias, RJ, Brazil); and hexa-hydrated nickel nitrate $\left(\mathrm{Ni}\left(\mathrm{NO}_{3}\right)_{2} \cdot 6 \mathrm{H}_{2} \mathrm{O}, 99.999 \%\right.$, Sigma-Aldrich, St. Louis, MO, USA). Every reagent was used without any further purification. All the experiments were performed with distilled water.

\subsection{Synthesis of SBA-15 Material}

The SBA-15 mesoporous material used in this study was obtained according to the methodology described in the literature [60], with modifications consisting of functionalizing the adsorbents with $\mathrm{Ag}(\mathrm{I})$ and $\mathrm{Ni}(\mathrm{II})$ salts. The adapted method for SBA-15 hydrothermal synthesis starts with the addition of TEOS and the triblock copolymer to $2 \mathrm{~mol} \mathrm{~L}^{-1} \mathrm{HCl}$ aqueous solution, followed by stirring the emerged mixture for $3 \mathrm{~h}$ at $40^{\circ} \mathrm{C}$. Next, TEOS was added dropwise (TEOS/P123 $\left.=2.0 \mathrm{w} / \mathrm{w}\right)$ and the obtained polymer-TEOS mixture was stirred for $24 \mathrm{~h}$ under the same conditions. The gel (molar composition of 0.00034 P123: 0.021 TEOS: $1.974 \mathrm{HCl}$ : $0.834 \mathrm{H}_{2} \mathrm{O}$ ) was transferred to a sealed Teflon autoclave container (Metaquímica, Jaraguá do Sul, SC, Brazil) and kept at $110{ }^{\circ} \mathrm{C}$ for a period of $48 \mathrm{~h}$. The final product was filtered, washed with $50 \mathrm{~mL}$ of ethanol/water (1:1) solution, and dried for $12 \mathrm{~h}$ at $100{ }^{\circ} \mathrm{C}$. SBA- 15 was calcined at $600{ }^{\circ} \mathrm{C}$ for $285 \mathrm{~min}$ at a rate of $2{ }^{\circ} \mathrm{C} \mathrm{min}^{-1}$.

The supports were doped via wet impregnation with $\mathrm{Ag}(\mathrm{I})$ and $\mathrm{Ni}(\mathrm{II})$ ions from $\mathrm{AgNO}_{3}$ and $\mathrm{Ni}\left(\mathrm{NO}_{3}\right)_{2} \cdot 6 \mathrm{H}_{2} \mathrm{O}$ salts, respectively. Ethanol solutions of $\mathrm{Ag}(\mathrm{I})\left(0.03 \mathrm{molL}^{-1}\right.$ and $0.12 \mathrm{molL}^{-1}$ for $2 \%(w / w)$ and $8 \%(w / w)$, respectively) and $\mathrm{Ni}(\mathrm{II})\left(0.05 \mathrm{~mol} \mathrm{~L}^{-1}\right.$ and 0.22 for $2 \%(w / w)$ and $8 \%(w / w)$, respectively) were prepared and added to $3.0 \mathrm{~g}$ of the calcinated material. The impregnation was performed in rotary evaporators (Fisatom, São Paulo, SP, Brazil) at $120 \mathrm{rpm}$ for $1 \mathrm{~h}$ at room temperature, and for $3.5 \mathrm{~h}$ more under progressive heating $\left(10^{\circ} \mathrm{C} / 30 \mathrm{~min}\right)$. The modified adsorbents were dried in a stove model Q 314B242 (Quimis, Diadema, SP, Brazil) at $120^{\circ} \mathrm{C}$ for $2 \mathrm{~h}$.

\subsection{Adsorbents' Characterization}

X-ray diffraction (XRD) patterns of the adsorbents were collected on a Bruker D2 Phaser equipment (Bruker AXS, Madison, WI, USA) using CuK $\alpha$ radiation $\left(\lambda=1.5406 \AA\right.$ ) at the $2 \theta$ ranges of $0-5^{\circ}$ and $5-90^{\circ}$, with $30 \mathrm{kV}$ filament, $10 \mathrm{~mA}$ current, Ni filter, and a LYNXEYE detector. Nitrogen adsorption/desorption isotherms at $77 \mathrm{~K}$ were used to determine the textural parameters of the adsorbents in a Quantachrome Nova apparatus (Boynton Beach, FL, USA). The specific surface area $\left(\mathrm{S}_{\mathrm{BET}}\right)$ was calculated using the Brunauer-Emmett-Teller (BET) equation and the pore size and volume were determined, respectively, by applying the Barrett-Joyner-Halenda (BJH) method to the desorption branch of the $\mathrm{N}_{2}$ isotherm at $\mathrm{P} / \mathrm{P}_{0}=0.996$.

Scanning transmission electron microscopy (STEM) analysis and mapping data were recorded in a Helios Nanolab 650 instrument (FEI, Brno, Czech Republic) with a high-angle annular dark-field (HAADF) detector, at $200 \mathrm{kV}$ and $200 \mathrm{nA}$. The microanalysis was carried out with an energy-dispersive X-ray (EDX) spectroscopy Super-X system (FEI, Brno, Czech Republic) provided with four X-ray detectors and an extreme field emission gun (X-FEG) beam. The morphology of the catalysts was evaluated by scanning electron microscopy (SEM) with field emission gun (FEG) images obtained by a SEM-FEG AURIGA microscope from ZEISS (Carl Zeiss, Oberkochen, BW, Germany) coupled to a Bruker Xflash Detector 410-M energy-dispersive X-ray (EDX) apparatus (Bruker AXS+, Madison, WI, USA). X-ray photoelectron spectroscopy (XPS) was performed by a Physical Electronics PHI 5700 spectrometer (Physical Electronics, Inc., Chanhassen, MN, USA) with non-monochromatic Al $\mathrm{K} \alpha$ radiation $(95.2 \mathrm{~W}, 15 \mathrm{kV}$, and $1486.6 \mathrm{eV})$ and a multi-channel detector. High-resolution spectra 
were recorded at a take-off angle of $45^{\circ}$ using a concentric hemispherical analyzer operating in constant-pass-energy mode at $29.35 \mathrm{eV}$, using a $720 \mu \mathrm{m}$ diameter analysis area. C1s peaks were used as an internal standard calibration peak at $284.8 \mathrm{eV}$ using the Multipak (version 9.6.0.15) software program (Physical Electronics, Inc., Chanhassen, MN, USA). Ag3d spectra were subsequently deconvoluted using PeakFit 4.12 software (Systat Software, Inc., Berkshire, UK) by applying Savitzky-Golay filter smoothing $(<20 \%)$, linear baseline, and Gaussian curves for iterative peak fitting in order to more accurately determine the binding energies of different element core levels.

\subsection{Preliminary Adsorption Tests}

High-sulfur content diesel fuel $S 1800$ (real diesel with $1800 \mathrm{mg} \mathrm{kg}^{-1}$ sulfur) from Clara Camarão Potiguar Refinery (Guamaré/RN, Brazil) was used to evaluate the adsorption processes. The sulfur removal capacity of the adsorbents was analyzed by a preliminary test performed in glass columns $(0.61 \mathrm{~cm} \times 30.0 \mathrm{~cm})$ with downward flow. Each adsorbent was placed in the column up to $9.0 \mathrm{~cm}$ in height (approximately $0.5 \mathrm{~g}$ of material), and $5.0 \mathrm{~mL}$ of diesel (constant volume) was subsequently added. Aliquots of $0.3 \mathrm{~mL}$ were collected from the bottom of the columns, and the sulfur content was measured in a total sulfur analyzer ultraviolet fluorescence (UVF) Antek Multitek spectrometer (PAC, L.P, Houston, TX, USA) according to ASTM D5453 methodology.

\subsection{Adsorption Study}

The S-compounds' removal from diesel was performed using the finite bath method, in which $0.3 \mathrm{~g}$ of the adsorbent and $8.0 \mathrm{~mL}$ of diesel fuel were mixed and stirred at $100 \mathrm{rpm}$ in a shaker apparatus (Solab, SL 180/DT, Piracicaba, SP, Brazil). Solutions containing different sulfur concentrations were applied in each test. The adsorbents were separated by centrifugation (15 min, $150 \mathrm{rpm}$ ) and the residual sulfur content in the supernatant was quantified by UVF spectroscopy. The sulfur adsorption capacity at equilibrium $\left(q_{e}\right)$ of each adsorbent was calculated using Equation (1) (Table 5).

The S-compound adsorption rate for the kinetic assessment was investigated at diverse time intervals (5-1600 min) and using a real diesel solution containing 500 ppm sulfur. Pseudo-first-order (Equation (2)), pseudo-second-order (Equation (3)), intraparticle diffusion (Equation (4)), Elovich (Equation (5)), and Boyd (Equation (6)) kinetic models were used to explain the adsorption mechanism $[47,61]$ (Table 5).

The adsorption equilibrium was evaluated by fitting the experimental adsorption data to Langmuir, Freundlich, Temkin, and D-R mathematical models in order to predict the equilibrium parameters and explain the adsorbent/adsorbate system. The Langmuir model (Equation (7)) describes specific homogenous sites and is applied in a monolayer adsorption process. The dimensionless constant, commonly known as a separation factor $\left(\mathrm{R}_{\mathrm{L}}\right)$ and proposed by Weber and Chakravorti, is presented in Equation (8). The Freundlich isotherm describes a heterogeneous system and can be applied to an adsorption of multiple layers with non-uniform distribution of the adsorption heat by the linear equation (Equation (9)) [21,61-63]. The Temkin isotherm suggests that the adsorption heat of the adsorbed molecules decreases linearly with the layer coverage due to the effects of indirect adsorbent/adsorbate interaction. The model can be expressed according to Equation (10). The Dubinin-Radushkevich (D-R) isotherm does not assume a homogeneous surface or constant adsorption potential. The linear form of the D-R isotherm model can be represented by the following (Equation (11)) [46,64]. The equations used in this work are described in Table 5. Origin 2019b software (OriginLab, Northampton, MA, USA) was used to adjust the linearized equations of the models for calculating the equilibrium parameters. 
Table 5. Mathematical equations and parameters.

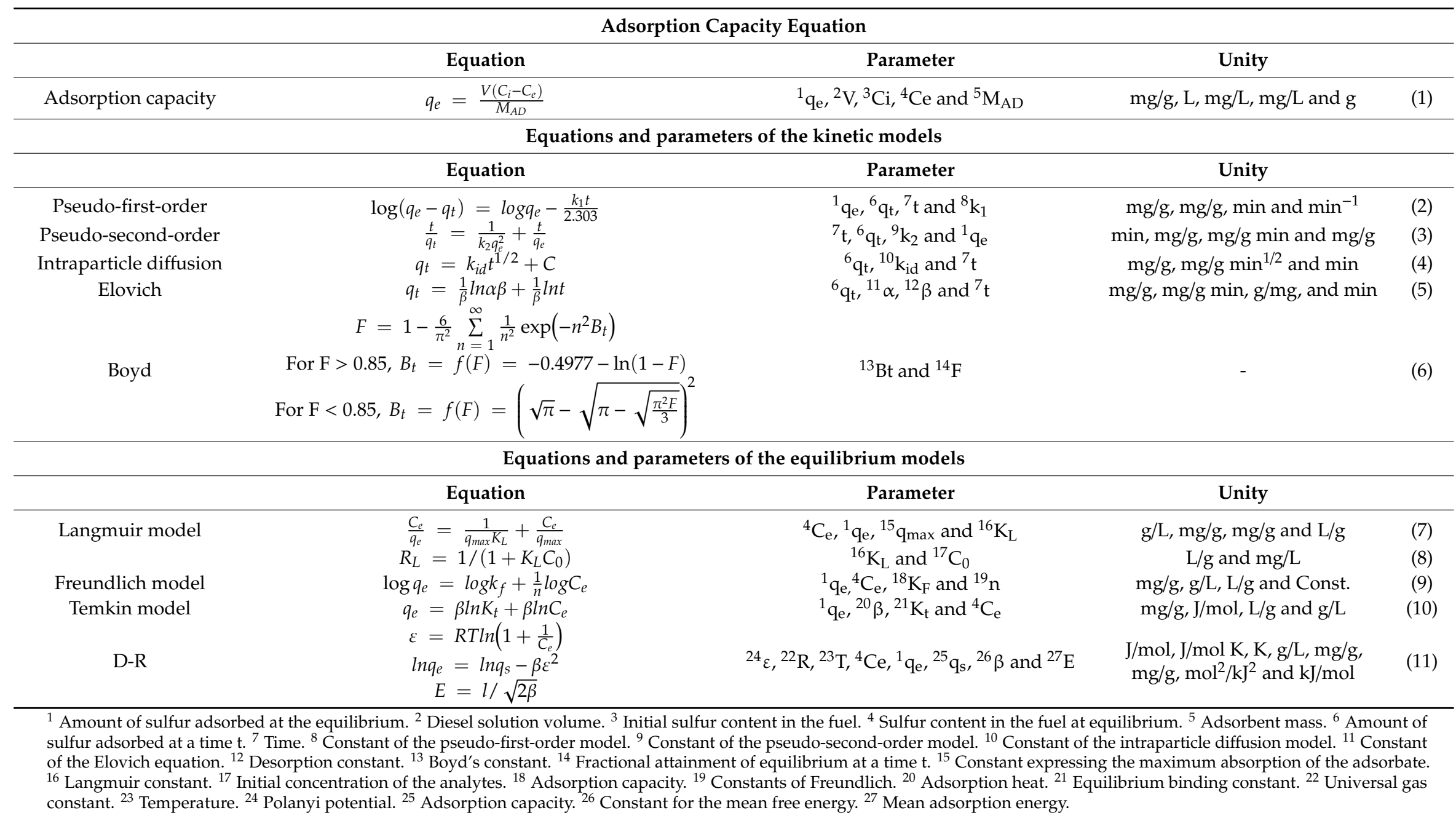




\subsection{Recycling Tests}

The regeneration methodology was adapted from Sales et al. (2019) [9]. One gram (1 g) of SBA-15 and 2AgSBA-15 residual adsorbents collected from the desulfurization tests was packed in apparatuses formed by a $10 \mathrm{~mm} \times 50 \mathrm{~cm}$ (diameter and height, respectively) glass column. The adsorbents were individually added up to $8 \mathrm{~cm}$ of fixed bed height. Then, $30 \mathrm{~mL}$ of the mixture containing acetone/chloroform/hexane were added in a 3:4:3 ratio, being defined after preliminary tests for the desorption of organic sulfur compounds. After eluting the solution, the adsorbents were washed and heated to about $343 \mathrm{~K}$ for $1 \mathrm{~h}$. The regeneration efficiency was determined for 6 cycles by a ratio between the percentage of sulfur removal reached in the first adsorption test and the percentage of sulfur removal reached by the regenerated adsorbent.

\section{Conclusions}

Characterization results were elucidated for the SBA-15 material, confirming the synthesis success. Modification with $\mathrm{Ag}(\mathrm{I})$ did not alter the morphology of the support. Preliminary desulfurization tests using the SBA-15 indicated better adsorption performance of the 2AgSBA-15 sample in comparison to the Ni-impregnated materials. HAADF-STEM-EDX and FESEM-EDX showed that there was uniform distribution of silver nanoparticles on the 2AgSBA-15 surface. The deconvoluted XPS spectra of 2AgSBA-15 before and after desulfurization revealed an interaction between the $\mathrm{Ag}(\mathrm{I})$ and metallic $\mathrm{Ag}$ sites and the sulfur molecules via $\pi$-complexation, thus controlling the chemisorption process suggested by the kinetic and equilibrium results, which were better fitted to the pseudo-second-order and Langmuir models, respectively.

The $\mathrm{R}_{\mathrm{L}}$ separation factor $\left(0<\mathrm{R}_{\mathrm{L}}<1\right)$ indicated that the adsorption of S-compounds on the surface of 2AgSBA-15 was favorable. In addition, the incorporation of Ag nanosites onto the SBA-15 support increased the adsorption capacity by approximately two times. Thus, the 2AgSBA-15 material presented high efficiency for the adsorptive desulfurization of real diesel samples and is able to be employed as a complementary method to the HDS method. The 2AgSBA-15 adsorbent presented a satisfactory regeneration after a total of six sulfur adsorption cycles enabled the reuse of this material for many times.

Supplementary Materials: The following are available online at http://www.mdpi.com/2073-4344/10/5/593/s1, Figure S1: Preliminary results for S-compound adsorption, Figure S2: Low-angle and wide-angle XRD patterns for the adsorbents with $8 \% \mathrm{Ag}, 2 \% \mathrm{Ni}$, and $8 \% \mathrm{Ni}$, Figure S3: Amount of sulfur adsorbed per time for 2AgSBA- 15 and AgSBA-15, Table S1: Major sulfur compounds in a straight run diesel oil (Hua et al. 2003), Table S2: Critical diameters for the major S-aromatic molecules in real diesel.

Author Contributions: Conceptualization, C.d.L., R.V.S., and L.S.d.C.; methodology, C.L., R.V.S., and A.B.F.C.; formal analysis, E.R.-C., L.M.A.C., M.M.U., and S.B.C.P.; investigation, C.L., R.V.S., L.S.d.C., H.O.M.d.A.M., and A.B.F.C.; resources, L.M.A.C. and M.M.U.; data curation, E.R.-C. and S.B.C.P.; writing-original draft preparation, C.L., R.V.S., A.B.F.C., H.O.M.d.A.M., and L.S.d.C.; writing-review and editing, C.L., R.V.S., H.O.M.d.A.M., A.B.F.C., E.R.-C., and L.S.d.C.; supervision, C.L., R.V.S., and L.S.d.C.; project administration, L.S.d.C.; funding acquisition, C.L., R.V.S., A.B.F.C., H.O.M.d.A.M., S.B.C.P., and E.R.-C. All authors have read and agreed to the published version of the manuscript.

Funding: This research was funded by Coordenação de Aperfeiçoamento de Pessoal de Nível Superior (CAPES-Brazil) for the financial support-finance code 001, Conselho Nacional de Pesquisa e Desenvolvimento (CNPq-Brazil), Ministerio de Ciencia, Innovación y Universidades, project RTI2018-099668-B-C22 and FEDER funds.

Acknowledgments: The authors thank the Energetic Technologies Laboratory (LTEN) and the Clara Camarão Potiguar Refinery (RPCC-Petrobras) for the diesel samples, the Program of Post-Graduation in Chemistry (PPGQ), and the Program of Post-Graduation in Materials Science and Engineering (PPGCEM) of the Federal University of Rio Grande do Norte.

Conflicts of Interest: The authors declare no conflict of interest. 


\section{References}

1. Morselli, D.; Campagnolo, L.; Prato, M.; Papadopoulou, E.L.; Scarpellini, A.; Athanassiou, A.; Fragouli, D. Ceria/Gold Nanoparticles in Situ Synthesized on Polymeric Membranes with Enhanced Photocatalytic and Radical Scavenging Activity. ACS Appl. Nano Mater. 2018, 1, 5601-5611. [CrossRef]

2. Campagnolo, L.; Lauciello, S.; Athanassiou, A.; Fragouli, D. Au/ZnO Hybrid Nanostructures on Electrospun Polymeric Mats for Improved Photocatalytic Degradation of Organic Pollutants. Water 2019, 11, 1787. [CrossRef]

3. Hernández-Maldonado, A.J.; Yang, F.H.; Qi, G.; Yang, R.T. Desulfurization of transportation fuels by

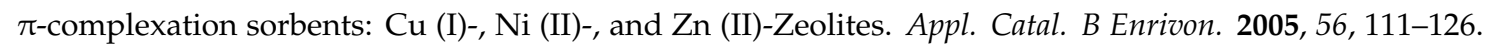
[CrossRef]

4. Subhan, F.; Aslam, S.; Yan, Z.; Zhen, L.; Ikram, M.; Ullah, R.; Etim, U.J.; Ahmad, A. Ammonia assisted functionalization of cuprous oxide within confined spaces of SBA-15 for adsorptive desulfurization. Chem. Eng. J. 2018, 339, 557-565. [CrossRef]

5. Aslam, S.; Subhan, F.; Yan, Z.; Xing, W.; Zeng, J.; Liu, Y.; Ikram, M.; Rehman, S.; Ullah, R. Rapid functionalization of as-synthesized KIT-6 with nickel species occluded with template for adsorptive desulfurization. Microporous Mesoporous Mater. 2015, 214, 54-63. [CrossRef]

6. Ahmadi, M.; Anvaripour, B.; Khosravi-NiKou, M.R.; Mohammadian, M. Selective denitrogenation of model fuel through iron and chromium modified microporous materials (MSU-S). J. Environ. Chem. Eng. 2017, 5, 846-860. [CrossRef]

7. Janus, R.; Wardrzyk, M.; Natkanski, P.; Cool, P.; Kustrowski, P. Dynamic adsorption-desorption of methyl ethyl ketone on MCM-41 and SBA-15 decorated with thermally activated polymers. J. Ind. Eng. Chem. 2019, 71, 465-480. [CrossRef]

8. Zhao, D.; Feng, J.; Huo, Q.; Melosh, N.; Fredrickson, G.H.; Chmelka, B.F.; Stucky, G.D. Triblock Copolymer Syntheses of Mesoporous Silica with Periodic 50 to 300 Angstrom Pores. Science 1988, 279, 548-552. [CrossRef]

9. Sales, R.F.; Moura, H.O.M.A.; Câmara, A.B.F.; Rodríguez-Castellón, E.; Silva, J.A.B.; Pergher, S.B.C.; Campos, L.M.A.; Urbina, M.M.; Bicudo, T.C.; Carvalho, L.S. Assessment of Ag Nanoparticles Interaction over Low-Cost Mesoporous Silica in Deep Desulfurization of Diesel. Catalysts 2019, 9, 651. [CrossRef]

10. Sareen, S.; Mutreja, V.; Pal, B.; Singh, S. Homogeneous dispersion of Au nanoparticles into mesoporous SBA-15 exhibiting improved catalytic for nitroaromatic reduction. Microporous Mesoporous Mater. 2015, 202, 219-225. [CrossRef]

11. Sikarwar, P.; Kumar, U.K.A.; Gosu, V.; Subbaramaiah, V. Catalytic oxidativedesulfurization of DBT using green catalyst (Mo/MCM-41) derived from coal fly ash. J. Environ. Chem. Eng. 2018, 6, 1736-1744. [CrossRef]

12. Liao, J.-J.; Bao, W.-R.; Chang, L.-P. An approach to study the desulfurization mechanism and the competitive behavior from aromatics: A case study on CeY zeolite. Fuel Process. Technol. 2015, 140, 104-112. [CrossRef]

13. Pan, F.; Zhang, B.; Ding, Y.; Wang, L.; Xie, F.; Cai, W.; Liu, S.; Zhou, J. New composite aerogel-like adsorbents for thiophene based on $\pi$-complexation. Sep. Purif. Technol. 2018, 192, 46-54. [CrossRef]

14. Hussain, A.H.M.S.; Tatarchuk, B.J. Mechanism of hydrocarbon fuel desulfurization using Ag/TiO2-Al2O3 adsorbent. Fuel Process. Technol. 2014, 126, 233-242. [CrossRef]

15. Souza, M.J.B.; Pedrosa, A.M.G.; Cecilia, J.A.; Gil-Mora, A.M.; Rodríguez-Castellón, E. Hydrodesulfurization of dibenzothiophene over PtMo/MCM-48 catalysts. Catalysis. Communications 2015, 69, 217-222.

16. Shan, J.-H.; Chen, L.; Sun, L.-B.; Liu, X.-Q. Adsorptive Removal of Thiophene by Cu-Modified Mesoporous Silica MCM-48 Derived from Direct Synthesis. Energy Fuels 2011, 25, 3093-3099. [CrossRef]

17. Subhan, F.; Aslam, S.; Yan, Z.; Ikram, M.; Rehman, S. Enhanced desulfurization characteristics of Cu-KIT-6 for thiophene. Microporous Mesoporous Mater. 2014, 199, 108-116. [CrossRef]

18. Bhanvase, B.A.; Veer, A.; Shirsath, S.R.; Sonawane, S.H. Ultrasound assisted preparation, characterization and adsorption study of ternary chitosan-ZnO-TiO2nanocomposite: Advantage over conventional method. Ultrason. Sonochemistry 2019, 52, 120-130. [CrossRef]

19. Prajapati, Y.N.; Verma, N. Adsorptive desulfurization of diesel oil using nickel nanoparticle-doped activated carbon beads with/without carbon nanofibers: Effects of adsorbate size and adsorbent texture. Fuel 2017, 189, 186-194. [CrossRef] 
20. Zhao, D.; Huo, Q.; Feng, J.; Chmelka, B.F.; Stucky, G.D. Nonionic Triblock and Star Diblock Copolymer and Oligomeric Surfactant Syntheses of Highly Ordered, Hydrothermally Stable, Mesoporous Silica Structure. J. Am. Chem. Soc. 1988, 120, 6024-6036. [CrossRef]

21. Wang, X.; Ji, G.; Song, C.; Zhang, H.; Gao, C. Surface hydroxylation of SBA-15 via alkaline for efficient amidoxime-functionalization and enhanced uranium adsorption. Sepatation Publ. Technol. 2019, 209, $623-635$. [CrossRef]

22. Socci, J.; Osatiashtiani, A.; Kyriakou, G.; Bridgwater, T. The catalytic cracking of sterically challenging plastic feedstocks over high acid density Al-SBA-15 catalysts. Appl. Catal. A Gen. 2019, 570, 218-227. [CrossRef]

23. Sales, R.F.; Moura, H.O.M.A.; Silva, S.R.B.; Souza, M.A.F.; Campos, L.M.A.; Rodríguez-Castellón, E.; Carvalho, L.S. Experimental and theoretical study of adsorptive interactions in diesel fuel desulfurization over Ag/MCM-41 adsorbent. Adsorption 2020, 26, 189-201. [CrossRef]

24. Shen, S.; Chen, J.; Koodali, R.T.; Hu, Y.; Xiao, Q.; Zhou, J.; Wang, X.; Guo, L. Activation of MCM-41 mesoporous silica by transition-metal incorporation for photocatalytic hydrogen production. Appl. Catal. B Environ. 2014, 150, 138-146. [CrossRef]

25. Kowalczyk, A.; Borcuch, A.; Michalik, M.; Rutkowska, M.; Gil, B.; Sojka, Z.; Indyka, P.; Chmielarz, L. MCM-41 modified with transition metals by template ion-exchange method as catalysts for selective catalytic oxidation of ammonia to dinitrogen. Microporous Mesoporous Mater. 2017, 240, 9-21. [CrossRef]

26. Chotirach, M.; Tungasmita, S.; Tungasmita, D.N.; Tantayanon, S. Titanium nitride promoted Ni-based SBA-15 catalyst for dry reforming of methane. Int. J. Hydrogen Energy 2018, 43, 21322-21332. [CrossRef]

27. Al-Fatesh, A.S.; Arafat, Y.; Imbrahim, A.A.; Atia, H.; Fakeeha, A.H.; Armbruster, U.; Abasaeed, A.E.; Frusteri, F. Evaluation of Co-Ni/Sc-SBA-15 as a novel coke resistant catalyst for syngas production via CO2reformingofmethane. Appl. Catal. A Gen. 2018, 567, 102-111. [CrossRef]

28. Valles, V.A.; Sa- ngasaeng, Y.; Martínez, M.L.; Jongpatiwut, S.; Beltramone, A.R. HDT of model diesel feed over Ir-modified Zr-SBA-15 catalysts. Fuel 2019, 240, 138-152. [CrossRef]

29. Chiang, H.-L.; Wu, T.-N.; Zeng, L.-X. Carbon material formation and residue characteristics of SBA- 15 and nickel impregnated SBA-15 as exemplified bya cetone decomposition. Microporous Mesoporous Mater. 2019, 279, 286-292. [CrossRef]

30. Sanches, S.G.; Flores, J.H.; Silva, M.I.P. Ti dispersion on SBA-15 porous host to enhance photocatytic hydrogen production. J. Mol. Struct. 2018, 1170, 9-17. [CrossRef]

31. Wang, S.; Wang, Z.; Wang, Y.; Xia, C.; Hong, E.; Bai, L.; Li, T.; Wang, B. Study on the controlled synthesis and photocatalytic performance of rare earth $\mathrm{Nd}$ deposited on mesoporous $\mathrm{TiO} 2$ photocatalysts. Sci. Total Environ. 2019, 652, 85-92. [CrossRef] [PubMed]

32. Bukhari, S.N.; Chong, C.C.; Teh, D.-V.N.V.; Ainirazali, N.; Triwahyono, S.; Jalil, A.A.; Setiabudi, H.D. Promising hydrothermal technique for efficient CO2 methanation over Ni/SBA-15. Int. J. Hydrogen Energy 2019, 44, 20792-20804. [CrossRef]

33. Park, S.J.; Lee, D.H.; Kang, Y.S. High temperature proton exchange membranes based on triazoles attached onto SBA-15 type mesoporous silica. J. Membr. Sci. 2010, 357, 1-5. [CrossRef]

34. Shahriary, M.; Veisi, H.; Hekmati, M.; Hemmati, S. In situ green synthesis of Ag nanoparticles on herbal tea extract (Stachys lavandulifolia)-modified magnetic iron oxide nanoparticles as antibacterial agent and their 4-nitrophenol catalytic reduction activity. Mater. Sci. Eng. C 2018, 90, 57-66. [CrossRef]

35. Kim, Y.H.; Lee, D.K.; Cha, H.G.; Kim, C.W.; Kang, Y.S. Synthesis and Characterization of Antibacterial Ag-SiO2 Nanocomposite. J. Phys. Chem. 2007, 111, 3629-3635. [CrossRef]

36. Misran, H.; Salim, M.A.; Ramesh, S. Effect of Ag nanoparticles seeding on the properties of silica spheres. Ceram. Int. 2018, 44, 5901-5908. [CrossRef]

37. Dutov, V.V.; Mamontov, G.V.; Zaikovskii, V.I.; Vodyankina, O.V. The effect of support pretreatment on activity of $\mathrm{Ag} / \mathrm{SiO} 2$ catalysts in low-temperature CO oxidation. Catal. Today 2016, 278, 150-156. [CrossRef]

38. Calderon, S.; Galindo, R.E.; Benito, N.; Palacio, C.; Cavaleiro, A.; Carvalho, S. Ag+ release inhibition from $\mathrm{ZrCN}-\mathrm{Ag}$ coatings by surface agglomeration mechanism: Structural characterization. J. Phys. D Appl. Phys. 2013, 46, 325303. [CrossRef]

39. Losurdo, M.; Bergmair, I.; Dastmalchi, B.; Kim, T.-H.; Giangregroio, M.M.; Jiao, W.; Bianco, G.V.; Brown, A.S.; Hingerl, K.; Bruno, G. Graphene as an Electron Shuttle for Silver Deoxidation: Removing a Key Barrier to Plasmonics and Metamaterials for SERS in the Visible. Adv. Funct. Mater. 2014, 24, 1864-1878. [CrossRef] 
40. Hu, L.; Yuan, H.; Zou, L.; Chen, F.; Hu, X. Adsorption and visible light-driven photocatalytic degradation of Rhodamine B in aqueous solutions by Ag@AgBr/SBA-15. Appl. Surf. Sci. Vol. 2015, 355, 706-715. [CrossRef]

41. Tang, H.; Li, W.; Zhang, T.; Li, Q.; Xing, J.; Liu, H. Improvement in diesel desulfurization capacity by equilibrium isotherms analysis. Sep. Purif. Technol. 2011, 78, 352-356. [CrossRef]

42. Grzelak, A.; Jarón, T.; Mazej, Z.; Michalowski, T.; Szarek, P.; Grochala, W. Anomalous chemical shifts in X-ray photoelectron spectra of sulfur-containing compounds of silver (I) and (II). J. Electron Spectrosc. Relat. Phenom. 2015, 202, 38-45. [CrossRef]

43. Khan Rao, R.A.; Khatoon, A. Aluminate treated Casuarina equisetifolia leaves as potential adsorbent for sequestering $\mathrm{Cu}(\mathrm{II}), \mathrm{Pb}(\mathrm{II})$ and $\mathrm{Ni}(\mathrm{II})$ from aqueous solution. J. Clean. Prod. 2017, 165, 1280-1295. [CrossRef]

44. Berger, A.H.; Bhown, A.S. Comparing Physisorption and Chemisorption Solid Sorbents for use Separating CO2 from Flue Gas using Temperature Swing Adsorption. Energy Procedia 2011, 4, 562-576. [CrossRef]

45. Saleh, T.A.; Sulaiman, K.O.; AL-Hammadi, S.A.; Dafalla, H.; Danmaliki, G.I. Adsorptive desulfurization of thiophene, benzothiophene and dibenzothiophene over activated carbon manganese oxide nanocomposite: With column system evaluation. J. Clean. Prod. 2017, 154, 401-412. [CrossRef]

46. Habibi, A.; Belaroui, L.S.; Bengueddach, A.; Galindo, A.L.; Díaz, C.I.S.; Peña, A. Adsorption of metronidazole and spiramycin by an Algerian palygorskite. Effect of modification with tin. Microporous Mesoporous Mater. 2018, 268, 293-302. [CrossRef]

47. Oliveira, M.F.; Silva, M.G.C.; Vieira, M.G.A. Equilibrium and kinetic studies of caffeine adsorption from aqueous solutions on thermally modified Verde-lodo bentonite. Appl. Clay SCI 2019, 168, 366-373. [CrossRef]

48. Langmuir, I. The constitution and fundamental properties of solids and liquids. Part I. Solids. J. Am. Chem. Soc. 1916, 38, 2221-2295. [CrossRef]

49. Choi, A.E.S.; Roces, S.; Dugos, N.; Arcega, A.; Wan, M. Adsorptive removal of dibenzothiophene sulfone from fuel oil using clay material adsorbents. J. Clean. Prod. 2017, 161, 267-276. [CrossRef]

50. Srivastav, A.; Srivastava, V.C. Adsorptive desulfurization by activated alumina. J. Hazard. Mater. 2009, 170, 1133-1140. [CrossRef]

51. Tang, K.; Hong, X.; Zhao, Y.H.; Wang, Y.G. Adsorption Desulfurization on a Nanocrystalline NaY Zeolite Synthesized Using Carbon Nanotube Templated Growth. Pet. Sci. Technol. 2011, 29, 779-787. [CrossRef]

52. Moosavi, S.E.; Dastgheib, S.A.; Karimzadeh, R. Adsorption of Thiophenic Compounds from Model Diesel Fuel Using Copper and Nickel Impregnated Activated Carbons. Energies 2012, 5, 4233-4250. [CrossRef]

53. Ren, X.; Miao, G.; Xiao, Z.; Ye, F.; Li, Z.; Wang, H.; Xiao, J. Catalytic adsorptive desulfurization of model diesel fuel using TiO2/SBA-15 under mild condition. Fuel 2016, 174, 118-125. [CrossRef]

54. Kong, L.; Zhang, T.; Yao, R.; Zeng, Y.; Zhang, L.; Jian, P. Adsorptive desulfurization of fuels with Cu(I)/SBA-15 via low-temperature reduction. Microporous Mesoporous Mater. 2017, 251, 69-76. [CrossRef]

55. Danmaliki, G.; Saleh, T.A. Effects of bimetallic Ce/Fe nanoparticles on the desulfurization of thiophenes using activated carbon. Chem. Eng. J. 2017, 307, 914-927. [CrossRef]

56. Subhan, F.; Aslam, S.; Yan, Z.; Liu, Z.; Etim, U.J.; Wadood, A.; Ullah, R. Confinement of mesopores within ZSM-5 and functionalization with Ni NPs for deep desulfurization. Chem. Eng. J. 2018, 354, 706-715. [CrossRef]

57. Câmara, A.B.F.; Sales, R.V.; Bertolino, L.C.; Furlanetto, R.P.P.; Rodríguez-Castellón, E.; Carvalho, L.S. Novel application for palygorskite clay mineral: A kinetic and thermodynamic assessment of diesel fuel desulfurization. Adsorption 2020, 26, 267-282. [CrossRef]

58. Jeon, H.-J.; Ko, C.H.; Kim, S.H.; Kim, J.-N. Removal of Refractory Sulfur Compounds in Diesel Using Activated Carbon with Controlled Porosity. Energy Fuels 2009, 23, 2537-2543. [CrossRef]

59. Bu, j.; Loh, G.; Gwie, C.G.; Dewiyanti, S.; Tasrif, M.; Borgna, A. Desulfurization of diesel fuels by selective adsorption on activated carbons: Competitive adsorption of polycyclic aromatic sulfur heterocycles and polycyclic aromatic hydrocarbons. Chem. Eng. J. 2011, 166, 166,207-217. [CrossRef]

60. Pudukudy, M.; Yaakob, Z.; Akmal, Z.M. Direct decomposition of methane over Pd promoted Ni/SBA-15catalysts. Appl. Surf. Sci. 2015, 353, 127-136. [CrossRef]

61. Bergaoui, M.; Nakhli, A.; Benguerba, Y.; Khalfaoui, M.; Erto, A.; Soetaredj, F.E.; Ismadji, S.; Ernst, B. Novel insights into the adsorption mechanism of methylene blue onto organo-bentonite: Adsorption isotherms modeling and molecular simulation. J. Mol. Liq. 2018, 272, 697-707. [CrossRef]

62. Liu, Y.; Ying, D.; Sanguansri, L.; Augustin, M.A. Comparison of the adsorption behavior of catechin onto cellulose and pectin. Food Chem. 2019, 271, 733-738. [CrossRef] [PubMed] 
63. Weber, T.W.; Chakravorti, R.K. Pore and solid diffusion models for fixed-bed adsorbers. AlChE J. 1974, 20, 228-238. [CrossRef]

64. Demiral, H.; Güngör, C. Adsorption of copper (II) from aqueous solutions on activated carbon prepared from grape bagasse. J. Clean. Prod. 2016, 124, 103-113. [CrossRef]

(C) 2020 by the authors. Licensee MDPI, Basel, Switzerland. This article is an open access article distributed under the terms and conditions of the Creative Commons Attribution (CC BY) license (http://creativecommons.org/licenses/by/4.0/). 